(c) American Dairy Science Association, 2002.

\title{
Energy Balance Profiles for the First Three Lactations of Dairy Cows Estimated Using Random Regression
}

\author{
M. P. Coffey, ${ }^{*}$ G. Simm, ${ }^{\star}$ and S. Brotherstone $†$ \\ *Animal Biology Division, Scottish Agricultural College, \\ West Mains Road, Edinburgh EH9 3JG, UK \\ †Institute of Cell, Animal and Population Biology, \\ University of Edinburgh, West Mains Road, Edinburgh, EH9 3JT, UK
}

\begin{abstract}
Daily animal solutions were predicted using random regression analysis for feed intake, milk yield, live weight, and condition score recorded on 189 cows at the Langhill Dairy Cattle Research Centre. All cows had three successive lactations. Energy balance for days 1 to 305 of each of the three lactations was calculated both from daily measures of feed intake and milk output and from weekly measures of live weight and condition score. Cows returned to positive energy balance at days 72,75 , and 95 in lactations 1,2 , and 3 , respectively, based on energy balance calculated from feed intake and milk output records (EB1), and at days 77, 83, and 73 based on energy balance calculated from body energy state changes (EB2). Correlations between energy balance at the same time in successive lactations ranged from 0.01 to 0.66 depending on the method of calculation and the stage of lactation.

Energy balance over three lactations was modelled using sinusoidal functions which were associated with individual cows and allowed to vary between cows. The parameters of these curves are potentially useful since they have a biological interpretation. The phase relates to the period from calving to return to positive energy balance, and the amplitude relates to the degree of body energy loss (and recovery). The sinusoidal functions fitted to the curve removed a significant proportion of the variation, but accounted for only $45 \%$ and $40 \%$ of the variation in EB1 and EB2, respectively.

The relationship between energy balance in the first three lactations is likely to be more complex than a simple linear function, but the profile of energy balance over the first three lactations may be a useful selection criteria in a multi-trait index. Energy balance profile over lactations one to three can be modelled with moderate accuracy using sinusoidal functions, and this warrants further research.
\end{abstract}

Received June 26, 2001.

Accepted November 26, 2001.

Corresponding author: M. P. Coffey; e-mail:m.coffey@ed.sac.ac.uk.

\begin{abstract}
Abbreviation key: $\mathbf{C S}=$ condition score, $\mathbf{E B 1}=$ energy balance calculated from feed intake and milk production records, EB2 = energy balance calculated from body energy state changes, $\mathbf{F I}=$ feed intake, LWT = live weight, $\mathbf{M Y}=$ Milk yield .
\end{abstract}

\section{INTRODUCTION}

The total energy required by a cow to produce the milk yield of one lactation can vary depending on the source of energy to the mammary gland because the cost of metabolic processing of different types of nutrients by the cow varies (Emmans, 1994). If the cow can consume sufficient energy in food on a daily basis, then the cost in energy terms is simply the cost of turning the daily feed into milk minus the cost of supporting the obligatory bodily functions of the cow. However, if the cow cannot or will not consume sufficient feed on a daily basis, the energy cost of producing milk must then include the energy cost of catabolizing body tissue to make it available for milk production. There is genetic variation in the profile of condition score (CS) of a bull's daughters (Jones et al., 1999), indicating that a cow may have a genetically determined body energy state that is in part a function of stage of lactation. In order to remain in a preferred body energy state at all stages of lactation, as suggested by genetic merit for body condition score, the cow must subsequently replace lost body energy. This replacement also has an energy cost of processing. Therefore, in addition to the cost of obligatory functions, the total energy cost of producing a whole lactation's worth of milk is the sum of the energy content of the milk and the cost of mobilizing and replacing body tissue.

The replacement of body tissue in modern dairy cows usually takes place later in the same lactation, once milk output begins to decline. If the cow is pregnant, yield is further depressed (Olori et al., 1997) as the fetus develops. Replenishment of body tissue in preparation for the next lactation creates competition for nutrients among the demands for current yield and the developing fetus. The use of body lipid as a nutri- 
tional buffer is a normal mammalian physiological process (Pond et al., 1999), but the biological rules determining priorities of use, or partitioning, of available nutrients in cows of different genetic merit for production and at different stages of lactation and gestation are unknown.

The term "energy balance" is often used to describe the body energy state of dairy cows, which is the outcome of daily energy flux; negative energy balance is associated with body energy loss and positive energy balance with body energy gain. Cows which lose body tissue, and hence energy, in early lactation usually return to positive energy balance at around 40 to 80 days post partum (Sutter et al., 2000; Coffey et al., 2001; Veerkamp et al., 2000). Kendrick et al. (1999) found that return to positive energy balance was at 21 days or 49 days with high or low energy diets, respectively. However, cumulative body energy loss in the first lactation is, on average, only fully recovered at around day 200 (Coffey et al., 2001). Continued growth is required through the dry period and into the second lactation in order to reach physiological maturity. Negative energy balance is related to some health traits (Collard et al., 2000), to resumption of reproductive activity (De Vries et al., 1999; Veerkamp et al., 2000), and to oocyte size and quality (Beam and Butler, 1999; Kendrick et al., 1999). Individual cows may not regain all lost body energy in the first lactation leading to a greater deficit to be replenished in the second. This may result in carryover effects from one lactation to the next, and on both yield and nonyield traits such as health and fertility.

It is important to view productivity over the cow's entire lifetime and not simply on the basis of a single lactation. Current and previous body energy state changes may create a legacy that affects current and future productivity and health and fertility. Parameters of the lactation curve are different between at least the first three lactations, although curve parameters from one lactation can be used to predict those of subsequent lactations. Friggens et al. (2000) found that parameters associated with peak lactation and the rate of decline after peak in the third lactation can be described as simple ratios of those parameters in the first and second lactations. This is important when considering energy balance across lactations for the same animals when measures are available only in the first lactation, or where subsequent lactation measures may be biased by selection. The use of random regressions and Fourier series allows modelling of cyclical changes in a trait over seasons (Meyer, 2000) and could be used to model lifetime (or at least multiple lactation) energy balance changes in dairy cows. Parameters of these cyclical functions might then be analyzed for relationships with traits of economic importance such as health, fertility, and survival.

The objectives of this study were: 1 ) to model phenotypic daily milk yield, fresh feed intake, live weight and condition score using random regression techniques and restricted maximum likelihood (REML) for traits measured at different times and with different frequencies on dairy cows from the Langhill Dairy Cattle Research Centre; 2) to combine daily estimates obtained in the first objective into an overall energy balance for each day of the first three successive lactations; 3$)$ to compare energy balance curves over three lactations; and 4) to investigate the feasibility of modelling energy balance in the first three lactations using harmonic analysis.

\section{MATERIALS AND METHODS}

Data on 189 animals were extracted from the database of Langhill records collected since 1990 and that had completed at least 26 weeks of the third lactation by July 1999. The data included records of milk production and composition, live weight (LWT), condition score (CS), and fresh feed intake (FI) for two lines of cows. The lines were selected either for $\mathrm{kg}$ fat plus protein [select line $(\mathrm{S})$ ], or selected to remain close to the UK average genetic merit for fat plus protein production [control line (C)]. Approximately equal numbers of $\mathrm{S}$ and $\mathrm{C}$ cows were housed together and offered either a high or a low concentrate diet for a minimum of 26 weeks and for a maximum of 38 weeks of each lactation. Details of the management regime and selection criteria are reported elsewhere (Pryce et al., 1999). Records for animals that had remained on the trial for their first three lactations were the only ones included, to enable the analysis of multilactation energy balance for the same set of animals. A separate data set was constructed for each of the four traits analyzed (milk yield, condition score, live weight, and feed intake). Milk yield (MY) data consisted of summed daily yield measured at morning and afternoon milking up to 305 days after calving. In order to eliminate recording errors and aberrant records due to illness or oestrus, milk records were removed from the main data set if the value at any milking was less than $3 \mathrm{~kg}$ or was more than three standard deviations different from the mean of all other records for the same parity at the same stage of lactation. This resulted in the removal of 710 records out of 568,380 individual daily recordings from 224 different animals. Of these, only 11 animals had more than 10 daily records removed. Condition score was assessed weekly on all cows by the same operator over 
Table 1. Number of observations per animal (max obs.), mean, minimum and maximum for all observations for each trait for each lactation.

\begin{tabular}{lllccc}
\hline \multirow{2}{*}{ Trait } & Lactation & $\begin{array}{l}\text { Max obs. } \\
\text { per animal }\end{array}$ & Mean & Min & Max \\
\hline Milk yield (kg/d) & 1 & 305 & 21.2 & 3.6 & 52.0 \\
& 2 & 305 & 25.5 & 3.1 & 58.4 \\
& 3 & 305 & 27.6 & 3.1 & 61.7 \\
Feed intake (fresh weight) & 1 & 141 & 44.7 & 5.0 & 80.0 \\
(kg/d) & 2 & 141 & 51.9 & 7.3 & 90.0 \\
& 3 & 141 & 54.3 & 5.2 & 90.0 \\
Condition score & 1 & 36 & 2.56 & 1.0 & 4.0 \\
& 2 & 36 & 2.38 & 0.5 & 4.5 \\
& 3 & 36 & 2.39 & 0.75 & 4.75 \\
Live weight (kg) & 1 & 36 & 557 & 395 & 710 \\
& 2 & 36 & 641 & 415 & 805 \\
& 3 & & & 460 & 870 \\
\hline
\end{tabular}

the entire period of record collection using a 0 to 5 scale with 0.25 intervals (Lowman et al., 1976), where 0 is thin and 5 is obese. Live weight was measured weekly after morning milking coincidentally with condition scoring. Food was available ad libitum and individual intakes were recorded through Calan Broadbent gates. Daily FI was calculated from each of four consecutive days (Monday to Thursday) of measurements of food offered and refused. Feed offered was weighed on one morning, and refusals weighed and removed the following morning. Feed offered was adjusted over time so that refusals were around $10 \%$ of the total offered. Cows observed to habitually waste food by throwing it were removed from the trial. Table 1 shows the number of observations for each trait for each lactation.

Variance component estimation was performed using a random regression model with the ASREML statistical package (Gilmour, 1998). As pedigree information was not included in the analysis, animal solutions are combined animal genetic and permanent environmental effects. The random regression model fitted in this study was:

$$
y_{i t}=F_{i t}+\sum_{m=0}^{f-1} \beta_{m} P_{m}(t)+\sum_{m=0}^{k-1} \lambda_{i m} P_{m}(t)+\varepsilon_{i t}
$$

where $\mathrm{F}_{\text {it }}$ represents fixed effects of genetic line (2 groups), feed group (2 groups), time of measurement (year and week of measurement), the covariates percentage North American Holstein genes (linear) and age at calving in months (linear and quadratic) for animal $i . \beta_{m}$ are the fixed regression coefficients; $\lambda_{\text {im }}$ are the random regression coefficients associated with the animal plus its permanent environment; and $\varepsilon_{i t}$ is the residual error associated with days since calving $t . \mathrm{P}_{\mathrm{m}}(\mathrm{t})$ is the $\mathrm{m}^{\text {th }}$ Legendre polynomial evaluated at $t$.
The parameters $f$ and $k$ are the order of the fixed and random polynomials, respectively. Legendre polynomials were used because they are easy to manipulate, have good convergence properties and, being orthogonal polynomials, correlations between coefficients are lower than between the coefficients of ordinary polynomials. The four traits analyzed separately by lactation were: milk yield, condition score, feed intake, and live weight. Residual, or measurement, errors were expected to have heterogeneous variances over each lactation, with larger variances at the beginning of lactation and around peak yield. Different residual errors were, therefore, associated with observations over time. Based on preliminary analyses, residual error classes were defined as days 1 to 6,7 to 9,10 to 12 , 13 to 15,16 to 29,30 to 99 , and 100 to 305 . Within classes, residual errors were assumed to be homogeneous. Ideally, we would have preferred to model the residual variances using a continuous function, but an attempt to do so failed due to problems with convergence.

Based on previous genetic analyses of these data (Coffey et al., 2001), fixed regressions, which model the general shape of the curve and are common to all animals, were fitted for all traits as polynomials of order 5 . Third and fourth order polynomials were used to model the animal effect, and the goodness of fit was compared using a likelihood ratio test based on the $\chi^{2}$ distribution, and a significance level of 0.05 with the number of degrees of freedom equal to the difference in the number of variance components to be estimated.

Animal solutions obtained from the analysis were used to calculate daily phenotypic values for all animals in the data set, for all traits for days of lactation 1 to 305. Energy balance was derived in two different ways for the same cows after converting all measures to energy equivalents using the effective energy sys- 
tem of Emmans (1994) with additional terms for the major organic components of milk. The first method of deriving energy balance (EB1) was based on predicted energy available from recorded feed consumption minus energy required for recorded daily milk production, and maintenance predicted from LWT and gut fill. The second method (EB2) used body protein and lipid changes predicted from LWT and CS. Details of the formulas used to convert traits to effective energy equivalents are given by Coffey et al. (2001). Using these formulas allows a comparison of methods of calculation and sources of data. Applying these formulas to data from successive lactations also allows an assessment of the usefulness of first lactation energy balance in predicting energy balance in the second and third lactation for each of the methods of calculation.

The component values used in the calculation of energy content of feed and milk were determined in two ways: as the average over the whole data set used for each trait, and from results of feed and milk analyses concurrent with the time period in which the food was eaten or milk produced. This enables a comparison of energy balance calculated using different data sources for the subsequent purpose of using national data where feed intake and feed energy analysis are not available. Feed samples were taken daily and pooled for weekly analysis of components. Milk samples were obtained weekly from both daily milkings, and analyzed separately by an official recording agency (Cattle Information Service, Scotland) using a Foss Milkoscan 605 (Foss, Denmark). Milk energy output for each day was calculated from daily yields, and weekly milk sample analysis and feed energy intake was calculated from feed intake and the latest feed analysis.

The effects of pregnancy on the prediction of body weight were accounted for in part by modelling conceptus total weight (fetus plus placenta plus fluid) using an exponential growth curve from day of conception. Jakobsen et al. (1957) showed that energy requirements for the conceptus of heifers rose exponentially through gestation. For lactations 1 to 3 , this curve resulted in a weight of conceptus at 280 days of gestation of 80,90 , and $100 \mathrm{~kg}$ respectively to account for assumed increases in weight of this component in larger cows. The daily predicted weight of conceptus was subtracted from empty body weight to reduce any upwards bias on body lipid estimation by the presence of conceptus.

A visual appraisal of a sample of energy balance curves over three lactations for individual cows suggested that a possible method of describing the fluctuations in energy balance across lactations might be by using sinusoidal functions. All cows calved approximately every 12 months in order to remain on the trial, so energy balance data were collected over the three lactation cycles approximately every 365 days. As cows regain body condition after calving at different rates, (i.e., the phase varies between cows), and cows have different total amounts of body energy loss, (i.e., the amplitude varies between cows), sinusoidal functions were associated with individual cows and allowed to vary between cows.

The model for the harmonic analysis of the data was:

$$
y_{i}=a+b T+c_{i}\left(\operatorname{Sin} \frac{2 \pi T}{365}\right)+d_{i}\left(\operatorname{Cos} \frac{2 \pi T}{365}\right)+e_{i}
$$

where $\mathrm{y}_{i}=$ energy balance for animal $i$ on day $\mathrm{T}$ (either EB1 or EB2); $\mathrm{T}$ = days since first calving; $a$ and $b$ are fixed regression coefficients which cater for a trend over time; $c_{i}$ and $\mathrm{d}_{i}$ are the random regression coefficients; and $\mathrm{e}_{i}=$ error term for animal ${ }_{i}$.

\section{RESULTS}

Table 1 gives the maximum number of observations per animal, and the mean and maximum trait values for each trait within lactation. For each lactation there was a maximum of 36 observations per animal for condition score and live weight, 141 for feed intake, and 305 for milk yield. As expected, means for all

Table 2. Residual error variance for each trait for each lactation (Lactations 1,2,3 = L1,L2,L3) by measurement error class (days). Figures given for condition score are multiplied by 100 .

\begin{tabular}{|c|c|c|c|c|c|c|c|c|c|c|c|c|}
\hline \multirow[b]{2}{*}{ Days } & \multicolumn{3}{|c|}{ Milk yield $\left(\mathrm{kg}^{2}\right)$} & \multicolumn{3}{|c|}{ Feed intake $\left(\mathrm{kg}^{2}\right)$} & \multicolumn{3}{|c|}{ Condition score $(* 100)$} & \multicolumn{3}{|c|}{ Live weight $\left(\mathrm{kg}^{2}\right)$} \\
\hline & L1 & L2 & L3 & L1 & L2 & L3 & L1 & L2 & L3 & L1 & L2 & L3 \\
\hline $1-6$ & 34.8 & 63.9 & 80.1 & 272.2 & 207.4 & 121.1 & 1.18 & 2.22 & 1.37 & 712 & 378 & 548 \\
\hline 7-9 & 16.8 & 33.6 & 42.2 & 76.0 & 50.7 & 39.4 & 0.58 & 2.26 & 1.54 & 157 & 216 & 372 \\
\hline $10-12$ & 8.9 & 15.7 & 23.8 & 41.7 & 40.8 & 37.7 & 0.37 & 1.02 & 1.16 & 325 & 262 & 139 \\
\hline $13-15$ & 3.9 & 9.9 & 14.1 & 38.7 & 16.8 & 24.0 & 0.42 & 0.77 & 1.67 & 164 & 63 & 176 \\
\hline $16-29$ & 2.6 & 5.7 & 8.6 & 17.9 & 19.0 & 24.5 & 0.81 & 0.66 & 0.94 & 131 & 118 & 158 \\
\hline 30-99 & 3.2 & 4.6 & 6.7 & 15.7 & 20.6 & 20.4 & 0.80 & 1.21 & 1.02 & 101 & 102 & 130 \\
\hline $100-305$ & 2.4 & 2.6 & 3.6 & 17.3 & 19.8 & 21.1 & 0.11 & 1.06 & 1.14 & 113 & 152 & 163 \\
\hline
\end{tabular}




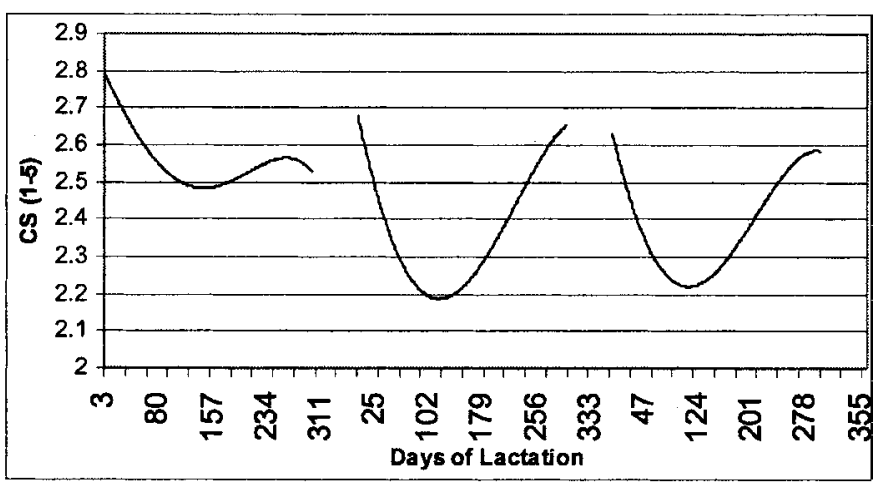

Figure 1. Least square mean phenotypic values by day of lactation for condition score.

traits apart from condition score rose with increasing lactation number. Condition score mean was highest in lactation 1, and similar for lactations 2 and 3. For all traits, a significant improvement in fit resulted when the order of the random polynomial was increased from 3 (quadratic) to 4 (cubic). All results are, therefore, based on the analyses that modelled the animal deviations using cubic polynomials.

Residual error variances are given in Table 2 for all error classes (days) for each trait in each lactation. For MY, the residual error variance increased for each class by lactation number in line with increased yield from later parity cows. For MY and FI, residual error variance declined as lactation progressed; whereas, for LWT it declined and then increased in the last error class. In lactation 1, the residual error variance for CS declined in early lactation and increased up to day 99. In the last measurement error class (100-305 days), it declined dramatically. In lactations 2 and 3, residual variation for CS followed a similar pattern to the other traits, although it did not decline in late lactation. Values of residual error variance found in this analysis are similar in magnitude to those obtained from a genetic analysis (Coffey et al., 2001) for the last two classes. These latter classes are the only ones that approximated to similar time periods in lactation in both analyses.

The mean animal solutions for CS, MY, FI, and LWT for days 1 to 305 of lactations 1, 2, and 3 are given in Figures 1 to 4, respectively. Figure 1 shows clearly that the reduction in CS as lactation progresses is less severe in the first lactation than in later lactations, and is commensurate with the lower yield, feed intake, and live weight exhibited by first lactation cows. The curves for LWT (Figure 4) suggest that an increase in body weight in lactation one occurs from the start of lactation, although the animal is losing body condition (Figure 1). This also occurs in later lactations, but in

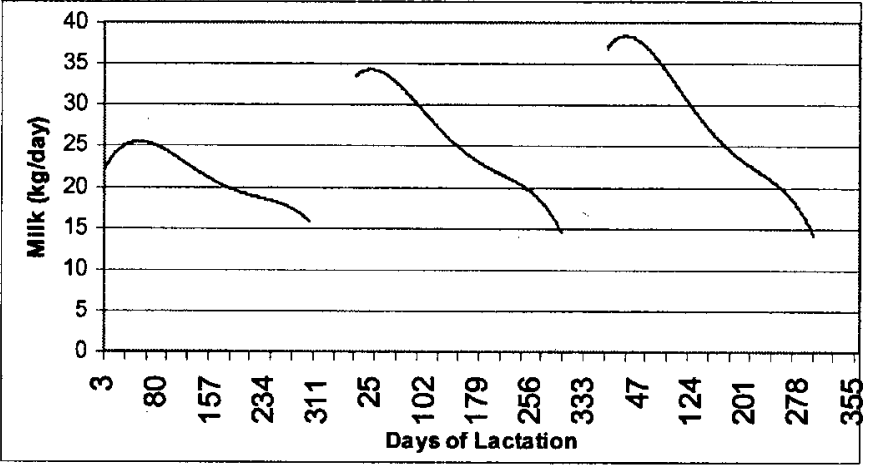

Figure 2. Least square mean phenotypic values by day of lactation for milk yield.

successive lactations there is a more pronounced loss of total live weight that includes condition loss in early lactation.

The mean energy balance of all cows for three lactations, using average values of milk and feed energy, is given in Figure 5 for EB1, and Figure 6 for EB2. Cumulative energy balance using EB2 is given in Figure 7 . When using the milk component and feed analysis concurrent with recording time, the mean energy balance is given in Figures 8 and 9 for EB1 and EB2, respectively. The less smooth appearance of Figures 8 and 9 compared to Figures 5 and 6 is because energy balance in Figures 8 and 9 is calculated from daily solutions that are smoothed by the process of calculation (random regressions), and feed and milk analysis that vary weekly. Figure 8 is, therefore, likely to be the most accurate description of energy balance over three lactations. Figure 9 is erratic because the prediction of body lipid relies, in part, on gut fill which, in turn, relies on feed composition. Since feed composi-

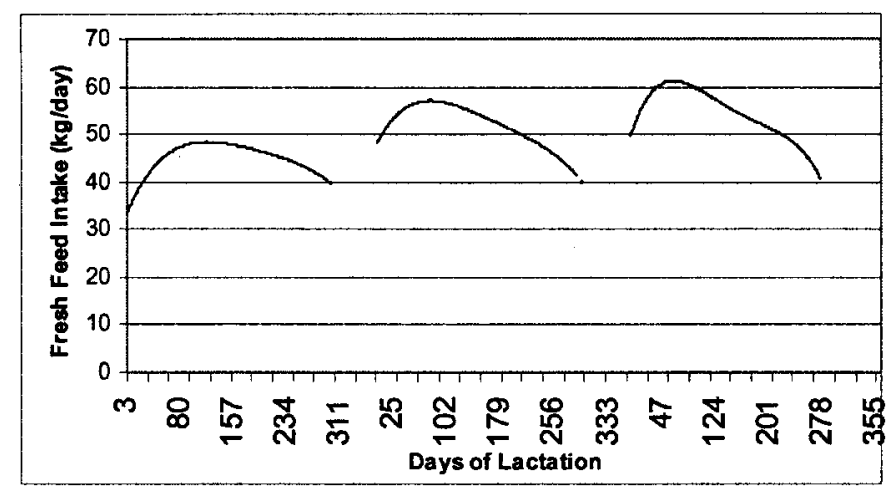

Figure 3. Least square mean phenotypic values by day of lactation for daily fresh feed intake. 


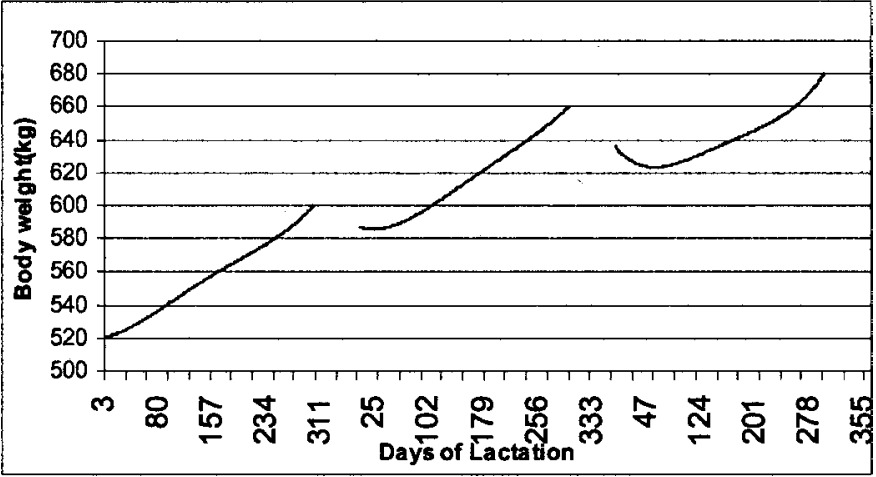

Figure 4. Least square mean phenotypic values by day of lactation for live weight.

tion analysis is conducted weekly, the estimate of daily gut fill and hence body lipid is more variable.

Table 3 gives correlations between energy balance estimates across lactations for selected days in milk. For EB1, correlations were generally moderate, particularly in mid-lactation, and varied from 0.21 (between lactations 1 and 3, day 7) and 0.66 (between lactations 1 and 2, day 120). For EB2, correlations were lower, and ranged from 0.01 to 0.44 . For cumulative EB2, correlations were low to moderate between lactations 1 and 2 , but low between lactations 1 and 3 , and 2 and 3 .

An initial analysis of both EB1 and EB2, fitting only the mean yielded a base model against which we could test the improvement in the goodness of fit when the trend line and sinusoidal functions were added to the model. For EB1, the inclusion of an overall trend line resulted in no significant improvement in fit. However, for EB2, the trend line removed a significant but small proportion (4\%) of the variation. For both energy bal-

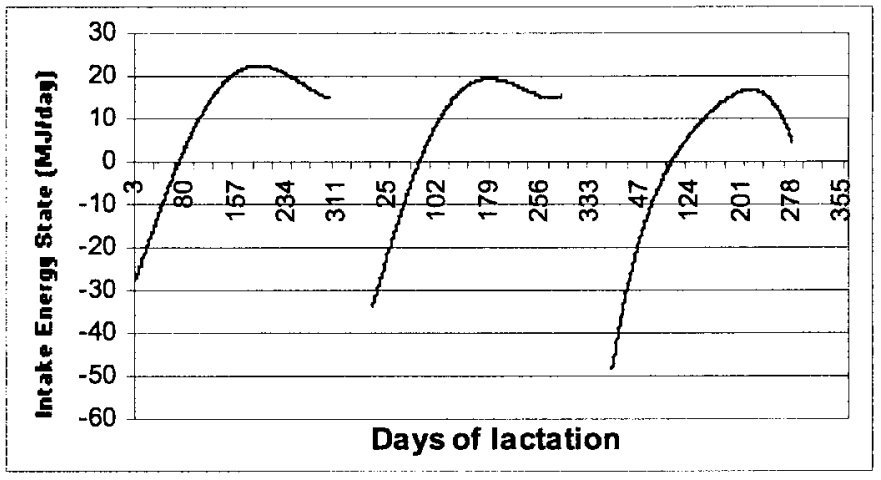

Figure 5. Energy balance calculated from energy intake and expenditure (EB1).

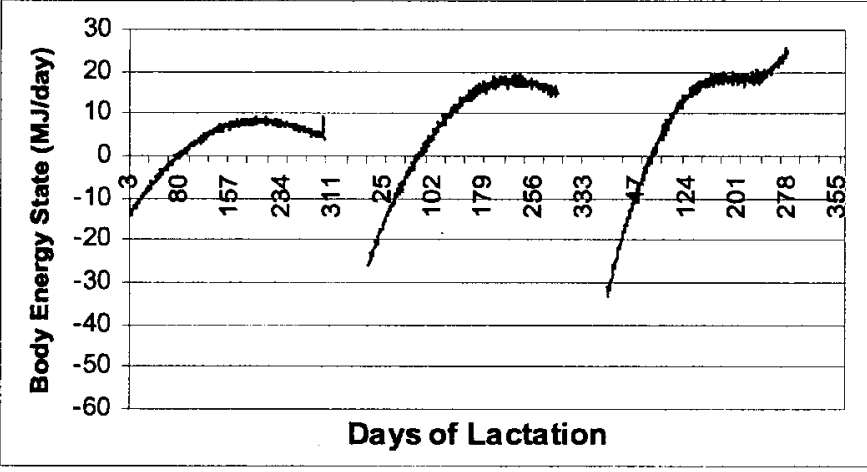

Figure 6. Energy balance calculated from body energy changes (EB2).

ance traits, the addition to the model of the sinusoidal functions resulted in a significant improvement in fit, but with only $45 \%$ of the variation in EB1 and $40 \%$ in EB2 being accounted for. The fitted sin/cosine curve for all cows for three lactations using EB1 is shown in Figure 10.

\section{DISCUSSION}

In this study, in order to avoid the effects of pregnancy, initially the data set consisted only of days 1 to 250 of lactation. This led to biologically non-sensible curves, particularly in the later stages of lactation. These were eliminated, as far as can be seen, by the use of complete data sets that span the entire period of observation. This confirms the findings of Pool et al. (2000) who concluded that random regression models did not predict the trajectory of the curve well unless all data relevant to the trajectory were used.

The condition scoring method of Lowman et al. (1976) uses a scale of 0 to 5 for cows that may vary in

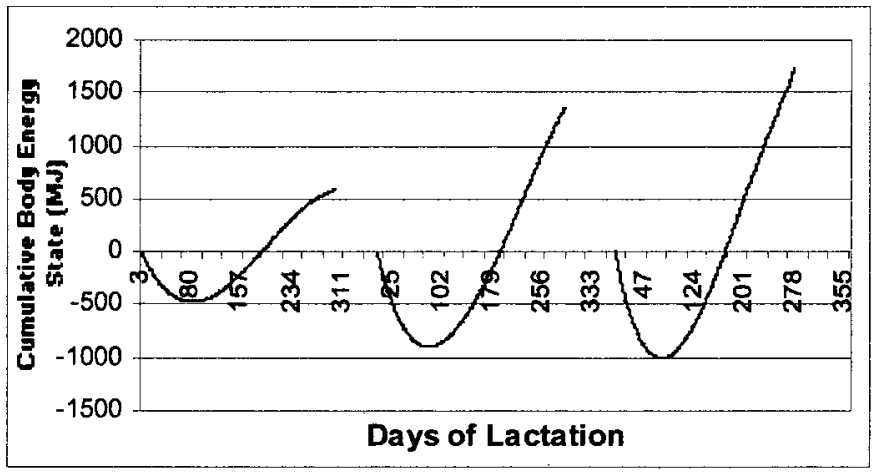

Figure 7. Cumulative long-term body energy state relative to body energy content at calving. 


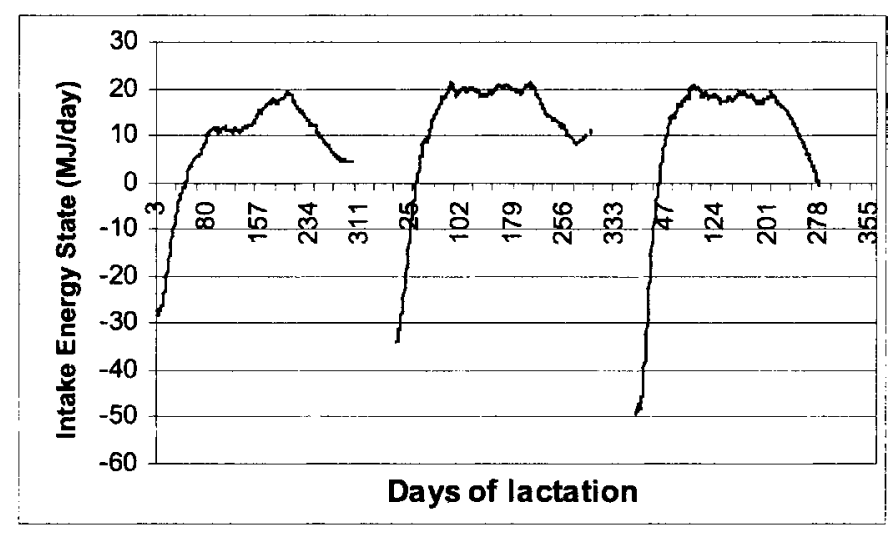

Figure 8. Energy balance calculated from energy intake and expenditure (EB1) and weekly milk and feed analysis.

weight. Therefore, CS predicts body lipid in a proportionate manner; therefore, body lipid estimation is sensitive to prediction or measurement of body weight. In the formula used in this study, body lipid is predicted from empty body weight which is dependent on unbiased estimates of gut fill. Towards the end of gestation, the conceptus accounts for an increasingly larger amount of body weight and may affect gut fill. Therefore, the conceptus must be properly accounted for in order to minimize error in prediction of body lipid using CS and empty body weight. In this study, the predicted weight of conceptus was subtracted from body weight before EB2 calculation. Energetic consumption by the conceptus was ignored, but this would only have a small effect on EB1 calculation.

The effect of pregnancy on the individual traits was ignored in this study since the data were obtained

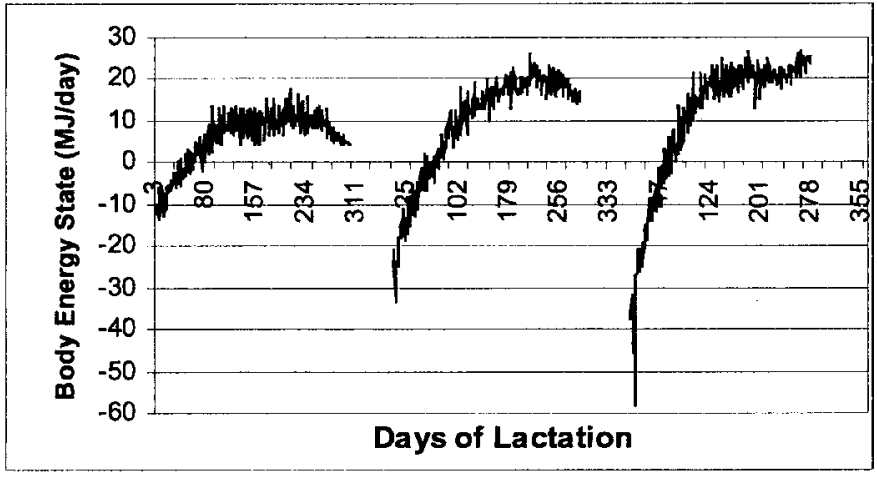

Figure 9. Energy balance calculated from body energy changes (EB2) and weekly milk and feed analysis.

from block-calving cows. All cows used in this study were within 4 months of calving of each other and were at approximately the same stage of lactation when pregnant. Therefore, the interaction between stage of lactation and gestation was assumed to be the same for all cows, leading to no bias. Olori et al. (1997) showed that yield was significantly reduced after the fifth month of gestation, but that yield was only reduced by more than $1 \mathrm{~kg}$ milk/day after 6 months of gestation. However, their study reported only the effects of pregnancy on milk yield and its components. It would be useful to know if there are significant effects of pregnancy on other traits, such as feed intake and particularly on body energy state. Of relevance to this study would be any three-way interaction of day of lactation, current or previous body energy state, and day of pregnancy. This would provide information on the genetic control of nutrient partitioning in ani-

Table 3. Correlations between daily energy balance (EB) estimates across lactations for individual cows. Lactations 1,2 , and $3=\mathrm{L} 1, \mathrm{~L} 2$, and L3, respectively.

\begin{tabular}{|c|c|c|c|c|c|c|c|c|c|}
\hline \multirow[b]{2}{*}{ Day } & \multicolumn{3}{|c|}{ EB1 } & \multicolumn{3}{|c|}{ EB2 } & \multicolumn{3}{|c|}{ Cumulative EB1 } \\
\hline & L1/L2 & L2/L3 & L1/L3 & L1/L2 & L2/L3 & L1/L3 & $\mathrm{L} 1 / \mathrm{L} 2$ & L2/L3 & L1/L3 \\
\hline 7 & 0.26 & 0.40 & 0.21 & 0.28 & 0.06 & 0.01 & 0.28 & 0.08 & 0.02 \\
\hline 14 & 0.28 & 0.41 & 0.23 & 0.31 & 0.08 & 0.02 & 0.29 & 0.08 & 0.02 \\
\hline 21 & 0.31 & 0.44 & 0.26 & 0.33 & 0.09 & 0.03 & 0.30 & 0.08 & 0.02 \\
\hline 28 & 0.34 & 0.46 & 0.29 & 0.35 & 0.11 & 0.05 & 0.31 & 0.08 & 0.02 \\
\hline 35 & 0.37 & 0.48 & 0.31 & 0.38 & 0.13 & 0.07 & 0.32 & 0.09 & 0.03 \\
\hline 42 & 0.40 & 0.51 & 0.34 & 0.40 & 0.15 & 0.08 & 0.33 & 0.10 & 0.03 \\
\hline 56 & 0.44 & 0.55 & 0.39 & 0.42 & 0.21 & 0.12 & 0.35 & 0.11 & 0.05 \\
\hline 70 & 0.48 & 0.58 & 0.42 & 0.38 & 0.23 & 0.16 & 0.37 & 0.13 & 0.06 \\
\hline 84 & 0.52 & 0.61 & 0.46 & 0.43 & 0.25 & 0.18 & 0.39 & 0.15 & 0.08 \\
\hline 98 & 0.55 & 0.64 & 0.49 & 0.38 & 0.20 & 0.20 & 0.40 & 0.17 & 0.10 \\
\hline 120 & 0.60 & 0.66 & 0.53 & 0.44 & 0.21 & 0.19 & 0.42 & 0.19 & 0.13 \\
\hline 150 & 0.65 & 0.66 & 0.53 & 0.39 & 0.17 & 0.16 & 0.43 & 0.22 & 0.16 \\
\hline 180 & 0.66 & 0.62 & 0.49 & 0.38 & 0.17 & 0.13 & 0.43 & 0.24 & 0.18 \\
\hline 210 & 0.63 & 0.60 & 0.45 & 0.30 & 0.18 & 0.09 & 0.44 & 0.24 & 0.19 \\
\hline 240 & 0.55 & 0.55 & 0.40 & 0.11 & 0.23 & 0.04 & 0.44 & 0.23 & 0.18 \\
\hline 270 & 0.33 & 0.37 & 0.31 & 0.05 & 0.23 & 0.03 & 0.41 & 0.21 & 0.16 \\
\hline
\end{tabular}




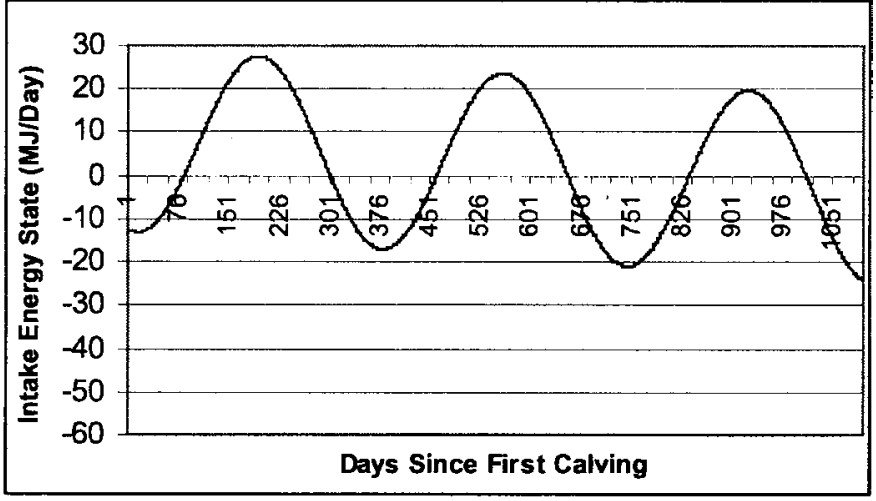

Figure 10. Energy balance using EB1 and sinusoidal fitting.

mals of different energy status when those animals depart from their 'preferred' energy status as defined by their genetic merit for body energy at that stage of lactation (Jones et al., 1999).

It has been reported that post partum reproductive activity may only resume once the nadir of negative energy balance has been reached (Butler and Smith, 1989; De Vries et al., 1999; Veerkamp et al., 2000), indicating that the rate of return to positive energy balance may be a useful indicator of resumption of reproductive activity and, by implication, possibly a useful selection objective. In this study, using EB1, cows returned to positive energy balance at days 72 , 75 , and 95 in lactations 1,2 , and 3, respectively. Using body state changes as an indicator, EB2 return to positive energy balance was at days 77,83 , and 73 for lactations 1, 2, and 3 . This discrepancy between the methods for calculating energy balance might be due to the inadequacy of the formulas to predict body lipid content from CS observations, the impact of estimation of gut fill on the prediction of body lipid from CS observations, bias in the observation of CS in different parity animals, inaccuracies in the estimation of dietary energy content, inaccuracies in the estimation of milk energy or maintenance energy output, or a combination of these. It would be useful for future research in this area to have revised values for the relationship between body lipid content and CS observations in modern dairy cows of different weight, stage of lactation, yield level, and conformation. This would enable more precise use of CS observations for farm management purposes and for research where energy balance is needed.

The rate of body energy loss and gain relative to the start of each lactation appears to change as lactation number increases (Figure 7). In the first lactation there will be a component of lipid-free growth that will require nutrients and increase the weight of the animal. This may slow down the apparent accretion of body fat since ingested energy will be partitioned to growth rather than deposited in fat depots that are measured by CS.

The correlation between energy balance on the same day of lactation in different parities is an indication of how accurately energy balance calculated from data gathered in one lactation predicts the subsequent lactation energy balance. The correlations between days in successive lactations change in their profile across lactation (Table 3). For EB1, correlations were lower at the beginning of lactation, rose to peak at around day 150 , then dropped slightly as lactation progressed. This peak in correlation corresponds approximately to the point of minimum condition score and may indicate that minimum condition score is less dependent on management or environment than is early or late lactation condition score when yields are lower. For EB2, the highest correlation occurred around 90 days, but followed a similar pattern as EB1.

Changes in energy balance over the lifetime of a cow may be a useful future selection objective since there are genetic differences in energy balance profiles between bull daughter groups in their first lactation (Coffey et al., 2001). A preliminary investigation indicated that lifetime energy balance may be modelled with low accuracy using sinusoidal functions. The parameters of the curves are useful since they have a biological interpretation. The phase relates to the period from calving to return to positive energy balance, and the amplitude relates to the degree of body energy loss (and recovery). Clearly, a declining amplitude over successive lactations means the cow is losing body energy over time and eventually may be compromised due to insufficient body energy reserves.

Here we used first order sinusoidal functions to model the periodic fluctuations over three lactations in an attempt to model energy balance over three lactations as a continuous trait even though the measurements do not span the dry period between lactations. We fitted a single sine and cosine function that did not produce a perfect fit. The lack of fit was associated with the fact that while the curve of the underlying biological process was cyclic, its shape was not symmetrical nor exactly sinusoidal, as there are differences in slope for the ascending and descending phases of the curve. Fitting a sine/cosine function creates a symmetrical curve and smooth continuum between lactation and dry period when the trait may, in fact, be discontinuous. Adding further sine and cosine terms with higher frequencies did not successfully eliminate the lack of fit. On the contrary, although with the addition of higher order sine and cosine terms the fit improved, the fitted curve became 'ripply' in 
appearance. A further complication is the lack of data throughout the dry period. Additional data on traits affecting energy balance collected during the dry period should enable us to identify a more suitable function and improve the fit.

A more detailed analysis is warranted in order to refine the fit of the curve, and a possible method of achieving this is to use circular splines. Smoothing splines are constrained by boundary conditions so that in the interval $(a, b)$ the value at $a$ is equal to the value at $b$. Analysis using circular splines is the same as harmonic analysis except that the higher frequency terms are given a lower weighting, resulting in a smooth curve. Although splines allow flexibility in the shape of the curve (White et al., 1999), the inclusion of these higher frequency terms makes it difficult to attribute any biological meaning to the coefficients of the curve. A biological interpretation of the coefficients is useful in that it allows us to make meaningful associations between them and other characteristics of importance, such as longevity, health, and reproductive success.

In this study, weekly milk sample analysis and feed analysis was available, and so, EB1 and EB2 were calculated using average values (Figures 5 and 6 ) and actual values for each cow for each day (Figures 8 and 9). This comparison enabled an assessment of the potential use of national measures of energy balance derived from linear type traits, condition score, and average values of milk and feed energy. The similarity in shape of these two sets of graphs demonstrates that on average, a single lactation value for feed energy and milk energy can be used when estimating average bull daughters' energy balance. This is important if EB2 is used to calculate energy balance from national data, since the estimation of empty body weight depends, in part, on an estimation of gut fill, which itself depends on estimation of feed analysis of digestibility.

A notable difference between EB1 and EB2 in both sets of graphs (Figures 5 and 6 and Figures 8 and 9) is that the rate of return to positive energy balance is lower for EB2. This would imply a lag between the animals 'true' energy state derived from estimates of energy flux using feed energy intake and milk energy output and its energy state predicted from body fat changes. An alternative suggestion is that body fat is being mobilized from fat stores assessed using CS, and then retained within the body. This repartitioning of nutrients may serve to support internal organs associated with increased metabolic activity and lactation.

Figures 8 and 9 also demonstrate more clearly the harmonic nature of the energy balance curve across lactations. At the end of each lactation, the curve tends towards zero energy balance as the animal approaches its desired energetic state. However, these data do not contain measurements taken during the dry period and, therefore, curve fitting is more difficult. Future experimentation to record appropriate measures through the dry period on individual cows would enable verification of the usefulness of fitting sinusoidal curves for energy balance throughout the animal's productive life.

\section{CONCLUSIONS}

The relationship between energy balance in the first three lactations is likely to be more complex than a simple linear function but the profile of energy balance over the first three lactations may be a useful selection criteria in a multi-trait index. Energy balance profile over lactations 1 to 3 can only be modelled with low to moderate accuracy using sinusoidal functions. This is due to the symmetrical nature of the function. Work is required to identify a better function relating to the underlying biological processes associated with energy balance over three lactations.

\section{ACKNOWLEDGMENTS}

We are grateful to the farm staff at Langhill for diligently recording data over a long time period that were used in this study. Professor W. G. Hill provided useful guidance and comments on the text, and Ian White is acknowledged for his help with the analysis. Professor John Oldham is acknowledged for contributing to discussion. SAC receives financial support from the Scottish Executive Environment and Rural Affairs Department.

\section{REFERENCES}

Beam, S. W., and W. R. Butler. 1998. Energy Balance, Metabolic Hormones, and Early Postpartum Follicular Development in Dairy Cows Fed Prilled Lipid. J. Dairy Sci. 81:121-131.

Butler, R. W., and R. D. Smith. 1989. Interrelationships Between Energy Balance and Postpartum Reproductive Function in Dairy Cattle. J. Dairy Sci. 72:767-783.

Cattle Information Service, 46 Underwood Road, Paisley, Scotland. PA14 1tJ.

Coffey, M. P., G. E. Emmans, and S. Brotherstone. 2001. Genetic Evaluation of Dairy Bulls for Energy Balance Traits Using Random Regression. Animal Science. In press.

Collard, B. L., P. J. Boettcher, J. C. M. Dekkers, D. Peticlerc, and L. R. Schaeffer. 2000. Relationships Between Energy Balance and Health Traits of Dairy cattle in Early Lactation. J. Dairy Sci. 83:2683-2690.

De Vries, M. J., S. Van Der Beek, L. M. T. E. Kaal-Lansbergen, W. Ouweltjes, and J. B. M. Wilmink. 1999. Modelling of Energy Balance in Early Lactation and the Effect of Energy Deficits in Early Lactation on First Detected Estrus Postpartum in Dairy Cows. J. Dairy Sci. 82:1927-1934.

De Vries, M. J., and R. F. Veerkamp. 2000. Energy Balance of Dairy Cattle in Relation to Milk Production Variables and Fertility. J. Dairy Sci. 83:62-69. 
Emmans, G. C. 1994. Effective energy: a concept of energy utilization applied across species. Br. J. Nutr. 71:801-821.

Foss Electric A/S, 69 Slangerupgade, DK 3400 Hillerod, Denmark.

Friggens, N. C., G. C. Emmans, and R. F. Veerkamp. 2000. On the use of simple ratios between lactation curve coefficients to describe parity effects on milk production. Livest. Prod. Sci. 62:1-13.

Gilmour, A. R., B. R. Cullis, S. J. Welham, and R. Thompson. 1998. ASREML User's Manual, October, 1998. New South Wales Agriculture, Orange Agricultural Institute., Orange, NSW, Australia.

Jakobsen, P. E., P. H. Sorensen, and H. Larson. 1957. Energy investigations as related to fetus formation in cattle. Acta Agric. Scand. 7:103.

Jones, H. E., I. M. S. White, and S. Brotherstone. 1999. Genetic evaluation of Holstein-Friesian sires for daughter condition score changes using a random regression model. Anim. Sci. 68:467-476.

Kendrick, K. W., T. L. Bailey, A. S. Garst, A. W. Pryor, A. Ahmadzadeh, R. M. Akers, W. E. Eyestone, R. E. Pearson, and F. C. Gwazdauskas. 1999. Effects of energy balance on hormones, ovarian activity, and recovered oocytes in lactating holstein cows using transvaginal follicular aspiration. J. Dairy Sci. 82:1731-1740.

Lowman, B. G., N. Scott, and S. Somerville. 1976. Condition Scoring of Cattle. Bulletin No. 6, East of Scotland College of Agriculture, Edinburgh, Scotland.
Meyer, K. 2000. Random regressions to model phenotypic variation in monthly weights of Australian beef cows. Livest. Prod. Sci. 65:19-38.

Olori, V. E., S. Brotherstone, W. G. Hill, and B. J. McGuirk. 1997. Effect of gestation stage on milk yield and composition in Holstein-Friesian dairy cattle. Livest. Prod. Sci. 52:167-176.

Pond, C. M., and E. A. Newsholme. 1999. Coping with metabolic stress in wild and domesticated animals. British Society of Animal Science Occasional Publication 24. 9-20.

Pool, M. H., L. L. G. Janss, and T. H. E. Meuwissen. 2000. Genetic parameters of legendre polynomials for first parity lactation curves. J. Dairy Sci. 83:2640-2649.

Pryce, J. E., B. L. Nielsen, R. F. Veerkamp, and G. Simm. 1999. Genotype and feeding system effects and interactions for health and fertility in dairy cattle. Livest. Prod. Sci. 57:193-201.

Sutter, F., and D. E. Beever. 2000. Energy and nitrogen metabolism in Holstein-Friesian cows during early lactation. Anim. Sci. 70:503-514

Veerkamp, R. F., J. K. Oldenbroek, H. J. Van der Gaast, and J. H. J. Van der Werf. 2000. Genetic correlation between days until start of luteal activity and milk yield, energy balance, and live weights. J. Dairy Sci. 83:577-583.

Veerkamp, R. F., and R. Thompson. 1999. A Covariance function for feed intake, live weight, and milk yield estimated using a random regression model. J. Dairy Sci. 82:1565-1573.

White, I. M. S., R. Thompson, and S. Brotherstone. 1999. Genetic and environmental smoothing of lactation curves with cubic splines. J. Dairy Sci. 82:632-638. 